\title{
Coordination between Understanding Historic Buildings and BIM Modelling: A 3D-Output Oriented and typological Data Capture Method
}

\author{
K. $\mathrm{Li}^{\text {a }}$, S.J. $\mathrm{Li}^{\mathrm{a}}$, Y.LIU ${ }^{\mathrm{b}}$, W.Wang ${ }^{\mathrm{a}}, \mathrm{C} . \mathrm{Wu}^{\mathrm{a}}$, \\ ${ }^{a}$ Institute Of Architectural History \& Theory, Tianjin University, Tianjin, China \\ -wu.cong@hotmail.com \\ ${ }^{\mathrm{b}}$ School of Computer Science and Technology, Tianjin University, Tianjin, China \\ -daisy_liu@tju.edu.cn
}

KEY WORDS: BIM, Structure-and-type Method, Structure tree, Type tree, Revit family manager

\begin{abstract}
:
At the present, in trend of shifting the old 2D-output oriented survey to a new 3D-output oriented survey based on BIM technology, the corresponding working methods and workflow for data capture, process, representation, etc. have to be changed.Based on case study of two buildings in the Summer Palace of Beijing, and Jiayuguan Pass at the west end of the Great Wall (both World Heritage sites), this paper puts forward a "structure-and-type method" by means of typological method used in archaeology, Revit family system, and the tectonic logic of building to realize a good coordination between understanding of historic buildings and BIM modelling.
\end{abstract}

\section{BACKGROUND}

Measured survey of historic buildings not only includes suitable measuring and representing technology and effective management,but also experience, cognition and evaluation of historic buildings in science, humanities, technology and art. It is not a process of passive recording, but integration of value judgment and information filtering activity which is easy to be ignored due to the restriction of the traditional 2D-output oriented survey. 3D image can be generated through comprehensive thought of the brain by the plan, elevation and section which is a fragment of $3 \mathrm{D}$ space. It is this continuous "translation" 2D- to 3D-based work that tends to ignore the $3 \mathrm{D}$ space relationship, constraint reference relationships between components and tectonic logic of building.

As BIM technology has been applied gradually and widely, it reflects the obvious advantages in data capture and recording. A way of thinking on tectonic logic of buildings is provided by Revit based on BIM that also actively contributes to active cognition, understanding of internal building logic. Therefore this paper puts forward a "structure-and-type method" to realize a good coordination between understanding of historic buildings and BIM modelling.

\section{STRUCTURE-AND-TYPE METHOD}

\subsection{General idea}

The route map of the "structure-and-type method" could be summarized as follows:

1. to survey a building in 3D based on typological method used in archaeology, Revit family system, and tectonic logic of buildings, taking each component or part as a unit;

2. to draw a "space-structure dendrogram" (abbreviated as "structure tree") and "component type dendrogram" (abbreviated as "type tree");

3. to make sketches and take survey notes based on the structure tree, and use both of them to reinforce understanding and support data capture and BIM modelling.

The structure tree, through locating each component in its "stratification", reflects structure, articulation, and space relation between components. The type tree, omitting space relations of components, mainly reflects typological relation 
between components, and essentially is an induction of dispersive components according to their shape and size, etc. The structure tree is no longer limited to $2 \mathrm{D}$ drawings, resulting in a good understanding of tectonic logic of buildings. And the type tree can be drew out after vertical and horizontal comparison of similar components, which can help research construction style, age, regional inherited characteristics in a higher level. The investigation method mentioned above with the structure tree and the type tree regarded as core, is just the structure-and-type method.

\subsection{Workflow}

Based on case study of two buildings in the Summer Palace of Beijing, and Jiayuguan Pass, the workflow is summed up as follows:

1. to draw the structure tree through observation, analysis, and record of components from their reference relationships step by step and then make sketches;

2. to conclude and merge the structure tree to the type tree, and amend each other during comparison;

3. To measure typical parts based on the two trees;

4. to check and perfect the two trees with measured data and prepare for the "family plan" for BIM modelling in Revit;

5. to perfect and form a chart and a preliminary investigation report and get ready for BIM modelling.

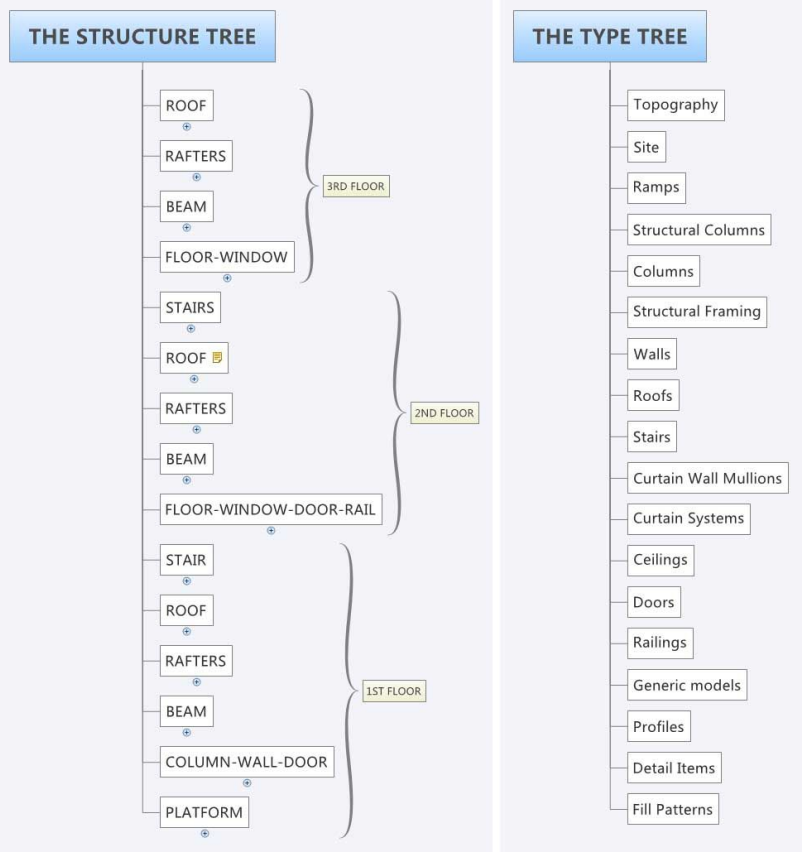

Figure 1. The structural tree and the type tree
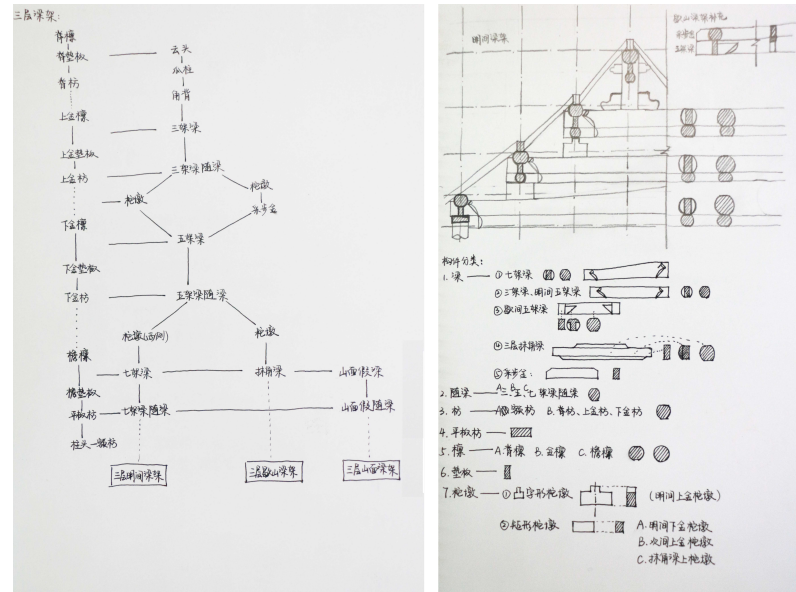

Figure 2. The sketches

Main results conclude: the structure tree and the type tree, sketches, measured data (consist of manual and instrument data and points cloud), relevant attribute information and image information etc. This paper focuses only on the two trees.

\subsection{The structure tree}

\subsubsection{General idea}

Its hierarchical nodes are following: units - component groups — components - family - type. Classify hierarchic order of each component and summarize it as family and type in order to reflect structure, articulation, and space relation.
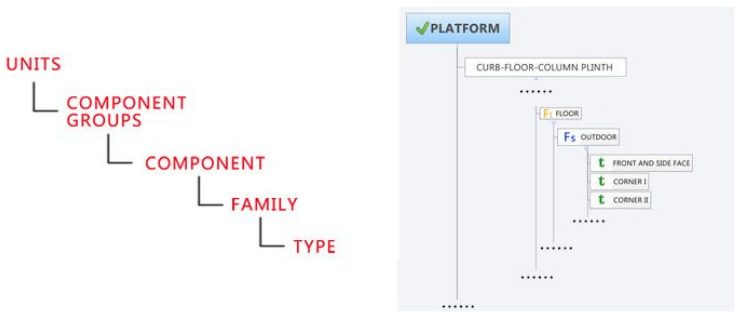

Figure 3. The hierarchic order

\subsubsection{Units}

Traditional historic buildings can usually be divided into three parts: platform, body and roof. Considering the internal space and structure, it can be further subdivided into platform, column-wall-door-window, beam, rafter and roof. For instance, the structure tree in level of units of Guanghua pavilion in Jiayuguan Pass is as follows: 


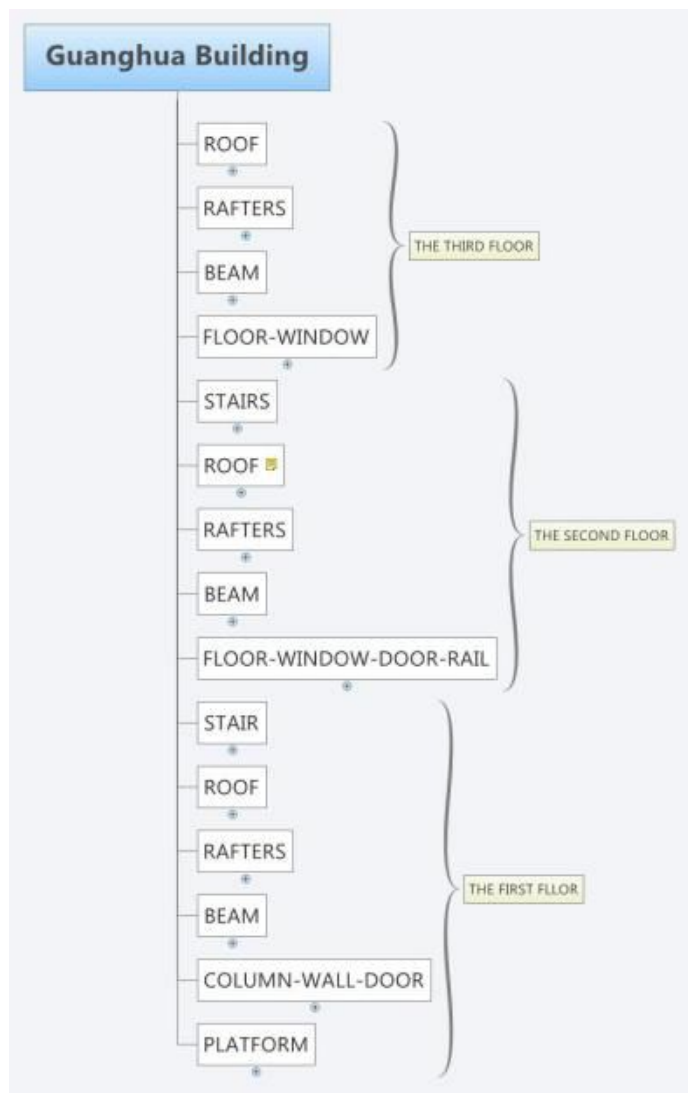

Figure 4. The units structure tree

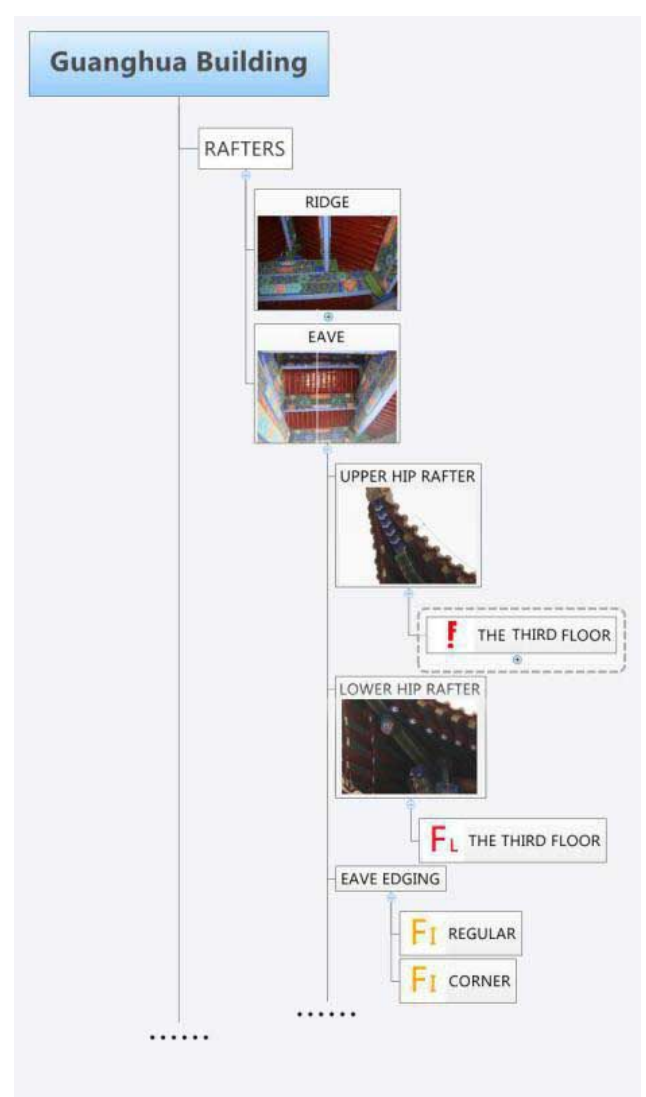

Figure 5. The structure tree for the rafters

\subsubsection{Component groups, component}

The division is determined according to different categories of architectural component properties, such as wall, door and ceiling. Take the rafters in the third floor of Guanghua Pavilion for example:

\subsubsection{Family and type}

Concepts of family and type still used directly from Revit associate with Revit principle, which is also one of the most key links in the whole measured survey.

It is the basic modeling idea in Revit that assembles components according to the tectonic logic of building in the "project manager". Meanwhile, these components must be given a classification system, which can be described as "category-family-style" layer by layer. Among them, the family is the most vital. In Revit, the family is indispensable, as information model can't exist without the family. In other words, it is absolutely necessary to classify components during modelling in Revit. So based on requirements of survey and measurement about historic buildings, organized classification of components measured should be carried on, as their own characteristics of historic buildings, with the help of typological methods.

Therefore, it is supposed to consider its position in components of the same kind, and the family and type should be classified in preliminary. For instance, all the columns of The Great Theater 
in the Summer Palace can be divided into family of 3 kinds owing to their different section form when we ignore the mortise-tenon. According to this, all the inner columns and eave columns of the second floor can be classified as "circle column": the eave columns of the third floor can be classified as "square column"; the eave columns of the first floor can be classified as "component column".

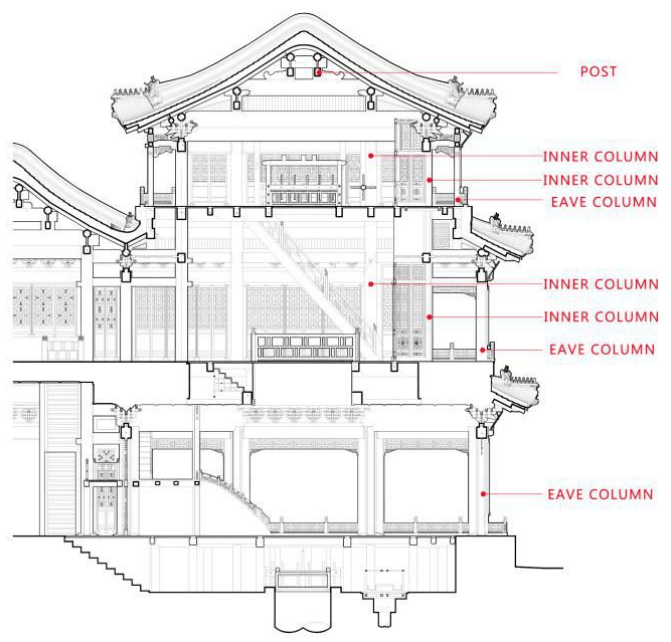

Figure 6. The columns mark

In order to distinguish between family and type in dendrogram, the following illustration will be used in this paper:

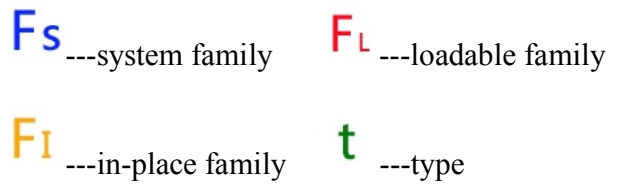

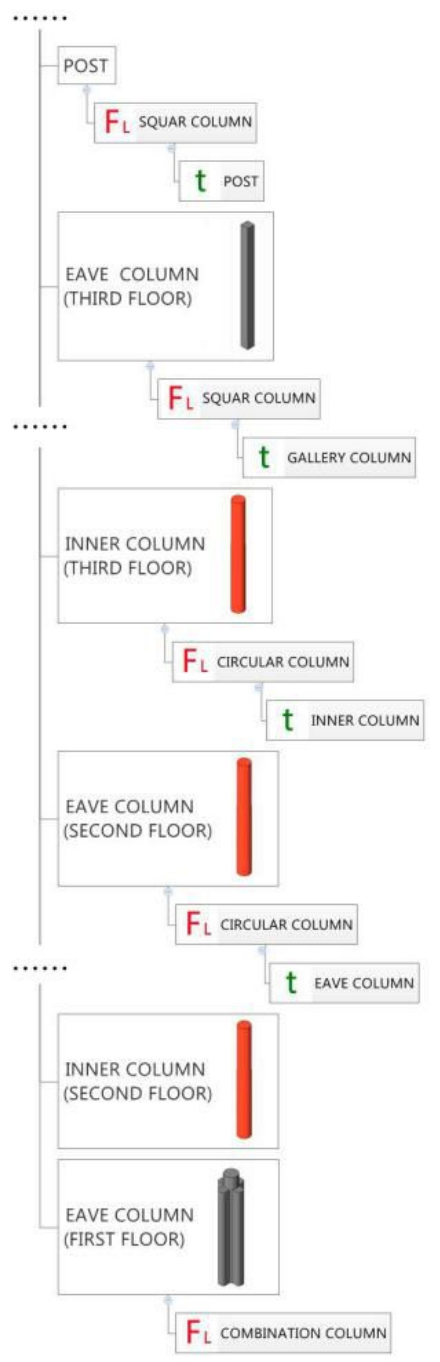

Figure 7. The columns classification

The following explanations need to be added:

1. It is usually based on geometrical properties in the classification of family and type, but sometimes it can be divided into a number of types owing to material and surface treatment if necessary.

2. When components of the same family appears in different positions, they should be associated with each other in the structure tree for the type tree.

3. The framework model for information index built in Revit is a set of idealized model with the mortise-tenon ignored, so as to reflect attributes of historic buildings. 


\subsection{The type tree}

\subsubsection{General idea}

"Category" is classification as tectonic logic of buildings in Revit, including generic models, site, ceiling, structure equipment, structure columns, columns, structure foundations, structural framing and profiles, etc. Essentially, the type tree, which reflects classification of components in typology, makes each family of the structure tree mapping corresponding category in Revit, and completes the family plan as a further foundation of family library.

\subsubsection{Methods}

Induce and organize the family and type in the structure tree of each building, and map them into categories in Revit, with its hierarchical nodes as following: category-family-type.
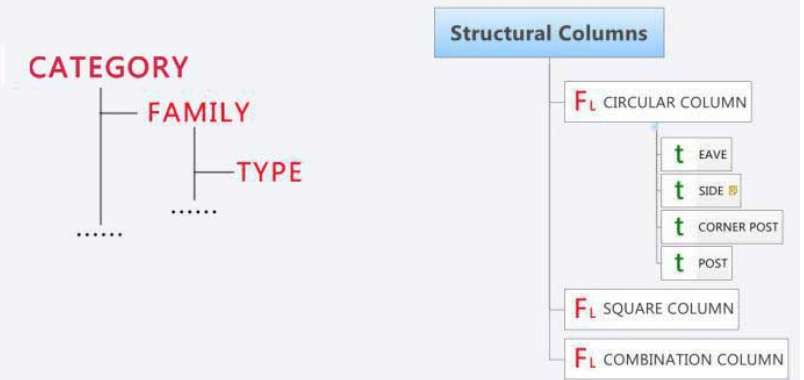

Figure 8. The hierarchical structure

Take the structure framing in the third floor of the great theater, Dehe Palace as example:

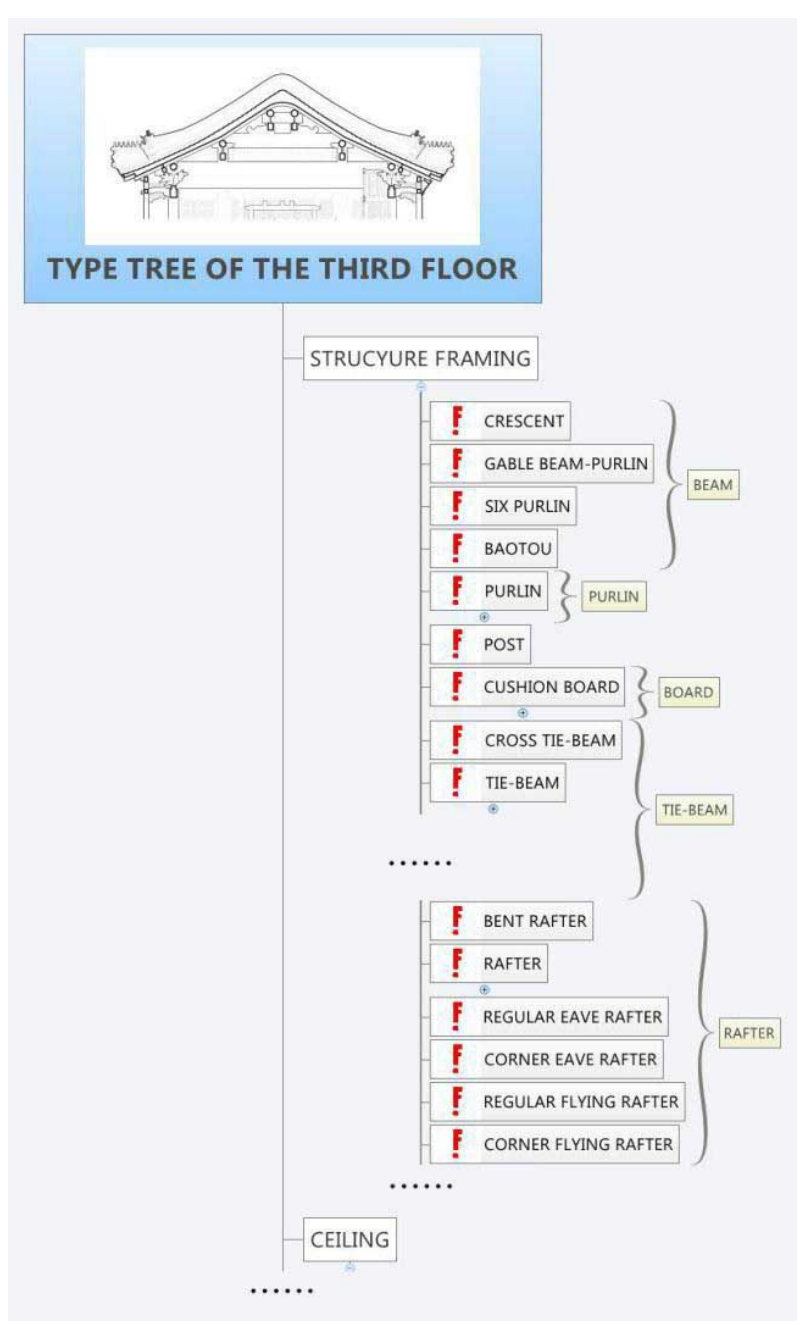

Figure 9. The type tree of $3^{\text {rd }}$ floor

\section{REVIT FAMILY MANAGER}

An independent platform needs to be built for more effective operation, and satisfy the requirements as follows:

1. Records and management of the structure and type tree completely;

2. Map from a structure tree to a type tree automatically or semi-automatically;

3. Merge of different type trees in image recognition technology;

4. Monitoring the creating and editing of family files (.rfa), supporting related searching, browsing, comparing, uploading and downloading of family members.

\section{CONCLUSION}

In summary, the structure tree is a representation of the whole building construction process based on tectonic logic of 
buildings, and a transition from traditional $2 \mathrm{D}$ drawings to $3 \mathrm{D}$ models. The type tree based on typological methods used in archaeology can be applied to different styles of buildings, groups, regions and even in a grander area. It is a new way shift from $2 \mathrm{D}$ to $3 \mathrm{D}$ outputs through "structure-and-type method" to realize a good coordination between understanding of historic buildings and BIM modelling, to observe, analyse, and record the buildings measured, to take survey notes, and to develop family library of Revit for historic buildings. Its academic value is inestimable when it is used as identification of time-space, distribution and evolution. At the same time, the framework model for information index built in Revit can directly serve in management of information recording, survey and design of protection project, construction records, etc.

\section{REFERENCES}

Gai,Jianmin, 2000. Modelling analysis. Science and technology, (1), pp. 17-21.

Zhao, Honghong, 2005. Information Architecture Design. China Architeture\&Building Press, Beijing, pp. 31-34.

Wang, Qiheng, Wu, Cong, Bai, Chengjun, 2006. Historic building survey. China Architeture\&Building Press,Beijing, pp. 7-10.

Wang, Lijun, 2005. Typological method used in architecture. Tianjin University Press, Tianjin. pp. 55-59.

Wu, Linlin, 2012. Study on the Lifecycle Management System of Architectural Heritage Information based on ArcGIS[D],Tianjin University

Li, Lijuan, 2012. Research on the Informatization of the Result Presentation of Architectural Heritage Survey[D],Tianjin University.

Liu, Huiyuan, 2013, Informationalizing the Architectures in Hexi Corridor based on CGB Technique[D], Tianjin University.

\section{APPENDIX}

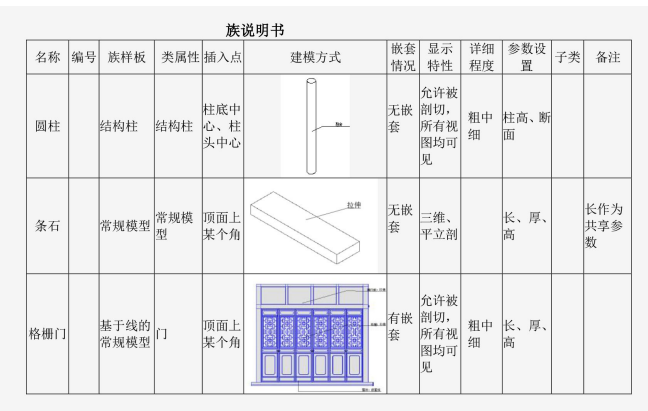

Figure 10. Family introductions

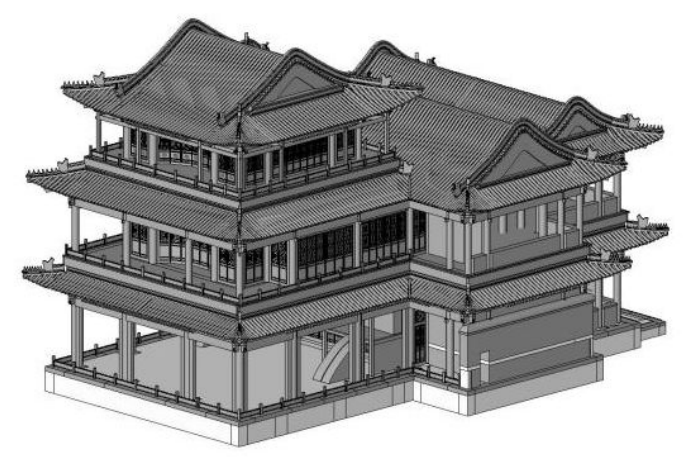

Figure 11. BIM model of The Great Theater

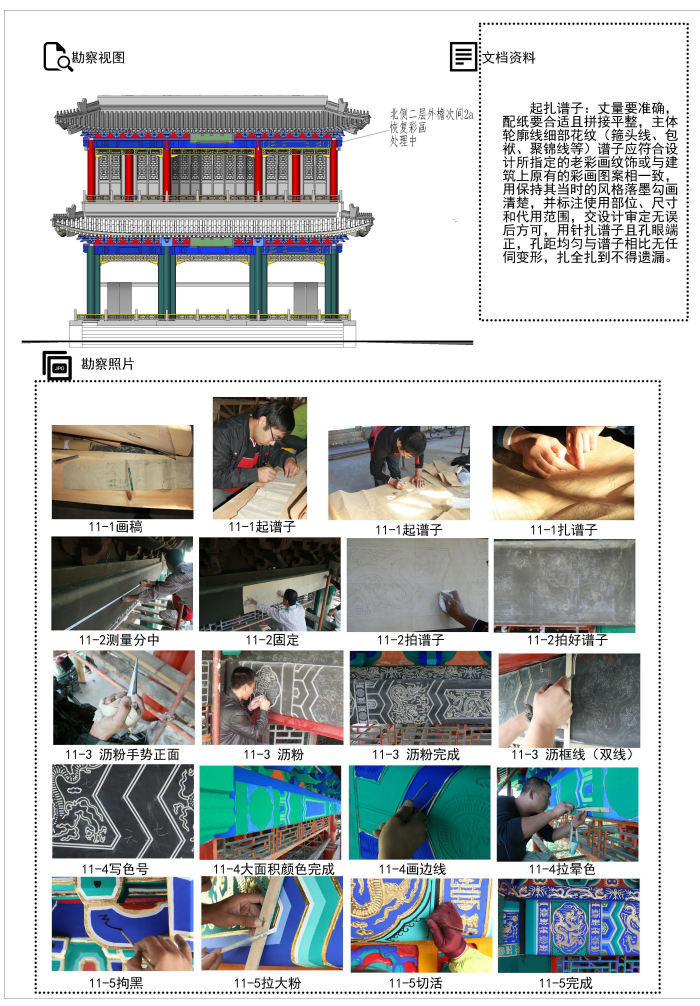

Figure 12. Survey report 